\title{
Changes in body composition and mRNA expression of ghrelin and lipoprotein lipase in rats treated with leuprolide acetate, a GnRH agonist
}

\author{
CARLOS OLVERA-SANDOVAL ${ }^{1}$, GABRIEL BETANZOS-CABRERA ${ }^{2}$, \\ RAFAEL CASILLAS-PEÑUELAS ${ }^{3}$ and J. LUIS QUINTANAR ${ }^{1}$
}

\begin{abstract}
${ }^{1}$ Neurophysiology Laboratory, Department of Physiology and Pharmacology, Basic Science Center, Universidad Autónoma de Aguascalientes, Ciudad Universitaria Aguascalientes, Ags 20131; ${ }^{2}$ Nutrigenomics Laboratory, Academic Area of Nutrition, Health Sciences Institute, Universidad Autónoma del Estado de Hidalgo, Pachuca de Soto, Hgo 42039;

${ }^{3}$ Department of Food Technology, Universidad Autónoma de Aguascalientes, Ciudad Universitaria Aguascalientes, Ags 20131, México
\end{abstract}

Received January 14, 2017; Accepted September 6, 2017

DOI: $10.3892 / e t m .2017 .5352$

\begin{abstract}
Leuprolide acetate (LA), a gonadotropin-releasing hormone (GnRH) agonist, was identified to cause changes in body weight in experimental and clinical trials; however, to date, the effect of LA on the body composition has not been properly assessed. The aim of the present study was to evaluate the long-term effect of LA administration on body composition and the mRNA expression of ghrelin and lipoprotein lipase (LPL) in rats. Ovariectomized (OVX), ovariectomized and LA-treated (OVX+LA), non-ovariectomized (CTRL) and non-ovariectomized but LA-treated (LA) rats were used. LA treatment was performed by intramuscular injection at $5 \mu \mathrm{g} / \mathrm{kg}$ every $72 \mathrm{~h}$ over 120 days. Analysis of body composition and mRNA expression of ghrelin and lipoprotein lipase were performed. The results indicated significant changes in body composition after treatment; in the OVX, LA, OVX+LA and CTRL group, the body weight was increased by $216.1,183.7$, 175.4 and $150.1 \%$, respectively, compared with baseline. The fat mass in the LA group was $14 \%$ higher than that in the CTRL group, while that in the OVX group was 19\% higher than that in the OVX+LA, and the fat-free mass was similar between the LA and CTRL as well as the OVX and OVX+LA groups. Following 120 days of treatment, the mRNA expression of ghrelin and LPL in the LA group was $20 \%$ higher than that in the CTRL group, while that in the OVX+LA was
\end{abstract}

Correspondence to: Dr J. Luis Quintanar, Neurophysiology Laboratory, Department of Physiology and Pharmacology, Basic Science Center, Universidad Autónoma de Aguascalientes, 940 Avenida Universidad, Ciudad Universitaria Aguascalientes, Ags 20131, México

E-mail: jlquinta@correo.uaa.mx

Key words: leuprolide acetate, ovariectomy, body composition, ghrelin, lipoprotein lipase downregulated in comparison with that in the OVX group. The results of the present study confirmed changes in body composition and mRNA expression of ghrelin and LPL caused by long-term administration of LA. LA may contribute to regulate food consumption and exert control over adipogenesis.

\section{Introduction}

Gonadotropin-releasing hormone $(\mathrm{GnRH})$ is a decapeptide originally discovered as a factor of hypothalamic origin that controls secretions of the anterior pituitary gland. GnRH has a direct effect on reproductive processes by regulating the synthesis and release of pituitary gonadotropins. In addition, it has been reported that GnRH has neurotrophic effects on dendritic spine density and cultured cerebral neurons of rat embryos by increasing growth and neurite number as well as modifying neurofilament expression $(1,2)$.

Several synthetic GnRH agonists, designed to have an increased biological effect, have been used for different therapeutic applications, including the treatment of cancer and precocious puberty as well as in vitro fertilization techniques (3).

Leuprolide acetate (LA) is a synthetic analog of GnRH composed of nine amino acids with a high biological effect due to its increased affinity to $\mathrm{GnRH}$ receptors and its prolonged action compared with those of endogenous GnRH $(3,4)$. This agonist has an increased resistance to enzymatic degradation and high protein binding due to its non-natural amino acids and prolonged serum half-life $(5,6)$. This agonist has been previously used for the same purposes as those mentioned above (7). Furthermore, it has been used as a neurological recovery factor in experimental autoimmune encephalomyelitis and in spinal cord injury (8-10).

Studies in humans and experimental models have evidenced that therapeutic application of GnRH or administration of agonists thereof has the secondary effect of increasing body weight $(8,9,11)$. The mechanisms involved in this process remain elusive; however, in the last two decades, different 
approaches have been proposed to elucidate the association between energy balance and adipogenesis with the aim of correlating endocrine and metabolic pathways. In this sense, the development of adipogenesis under non-pathological conditions corresponds with a high food consumption and loss of physical activity. Under this concept, ghrelin an orexigenic peptide have a fundamental role, acting on the brain to regulate food intake, body weight, adiposity and glucose metabolism (12). Furthermore, lipoprotein lipase (LPL) is an enzyme with numerous physiological activities, which mainly include the regulation of fatty acid supply to various tissues for either storage or oxidation (13). Changes in ghrelin and LPL expression depend on physiological stages and under stimuli by GnRH agonists, this condition may be favored to increase or suppress food consumption and changes in body weight. However, it is necessary to know the main changes in body composition that occur in the treatment with this agonist and the implications this may have in neuroregeneration studies, where weight gain is possibly associated with a better recovery or similarly, in other therapeutic applications, such as oncological, fertility or precocious puberty treatments, in which nutritional care is necessary in order to control undesired effects. The present study hypothesized that long-term use of LA may generate changes in body composition and modify the mRNA expression of ghrelin and LPL, two important molecules with high repercussion in the control of hunger and adipogenesis. In order to confirm this hypothesis, the aim of the present study was to evaluate a long-term effect of LA administration on body composition and determine the mRNA expression of ghrelin and LPL in non-ovariectomized and ovariectomized rats.

\section{Materials and methods}

Animal groups and housing conditions. A total of 96 female Wistar rats (weight, 120-150 g; age, 6 weeks) were obtained from the bioterium of the Universidad Autónoma de Aguascalientes (Aguascalientes, México) and treated according to the Guide for the Care and Use of Experimental Animals by the USA National Institutes of Health. They were maintained in separated cages (4 rats/cage of $50 \times 50 \times 18 \mathrm{~cm}$ ) under controlled conditions (temperature $23 \pm 2^{\circ} \mathrm{C}$; relative humidity $48 \%$ ) with a $12 \mathrm{~h}$ alternate light/dark cycle. They were provided a diet of standard rodent pellets (Purina Nutricubes ${ }^{\circledR}$; Nestle, Vevey, Switzerland) and water ad libitum. The animals were divided into four groups: Untreated (CTRL group), treated with LA (LA group), ovariectomized (OVX group) and ovariectomized treated with LA (OVX+LA group). All rats were habituated for 10 days prior to the experiment. The present study received approval from the Ethics Committee of the University of Aguascalientes (Aguascalientes, México).

Ovariectomy and LA administration. On the 10th day of habituation, two groups of animals were surgically ovariectomized. The animals were then kept in a stable and clean environment and were allowed to recover from the surgery for 10 days. For animals in the LA and OVX+LA groups, the treatment with LA (Sigma-Aldrich; Merck KGaA, Darmstadt, Germany) began on day 20 with by intramuscular administration of $5 \mu \mathrm{g} / \mathrm{kg}$ in $0.1 \mathrm{ml}$ saline solution $(0.9 \% \mathrm{NaCl})$ every
3 days until day 120. The other two groups, CTRL and OVX, received only saline solution with the same treatment schedule.

Murinometric evaluations and nutritional measurements. Food consumption $(\mathrm{g} / 24 \mathrm{~h} / 100 \mathrm{~g})$ was measured daily at the same time (between 09:00 and 10:00 h) and body weight was measured once a week to adjust the LA dose and to observe weight changes in treated and non-treated groups over the course of the experiment. Food was weighed in a digital balance $(500 \mathrm{~g}$ capacity x0.1 g; V31X501; Ohaus, Parsippany, NJ, USA). Body length (nose-anus length) was determined in all groups at 0, 20, $40,60,80,100$ and 120 days of the experiment with a metric tape fixed to a worktable. Body weight and body length were used to determine body mass index (BMI; $\mathrm{g} / \mathrm{cm}^{2}$ ) and ponderal index (PI; $\left.\mathrm{g} /{ }^{3} \sqrt{\mathrm{cm}}\right)$. Animal weight and food consumption was used to determine the specific rate of body mass gain in $\mathrm{g} / \mathrm{kg}$. All measures were determined according to equations described by Novelli et al (14), where the specific rate of body mass gain is defined as follows: Body mass gain $(\mathrm{g} / \mathrm{kg})=\mathrm{dM} / \mathrm{Mdt}$, where $\mathrm{dM}$ represents the gain of body weight during $\mathrm{dt}=\mathrm{t} 2-\mathrm{t} 1$ and $\mathrm{M}$ is the rat body weight at the time-point $\mathrm{t} 1$.

Body composition analysis in vivo. Body composition changes were registered in vivo throughout the different evaluation periods. To determine body density, hydrostatic weighing was performed every 20 days until day 120 as reported by Hohl et al (15). In brief, a device was designed with two graduated cylinders linked by a flexible hose were the rat was placed inside of one and changes in water volume in both cylinders were recorded. Recommendations for calibration and animal measurements were followed. Once the animal's density was determined, a densitometry-based equation was used to calculate the fat mass (FM) (16). The data obtained were converted to grams in order to compare the values with those from the dissection study. In the present study, the fat-free mass (FFM) was considered as the difference between total body weight and FM.

Carcass analysis and chemical lipid extract. Every 20 days, four rats from each group were sacrificed under anaesthesia. Blood samples were collected from the central aorta and weighed to calculate the residual mass. Rats were eviscerated and the skin was completely dissected from the neck region to the front and rear trunnions. All components were weighed using a calibrated balance (Ohaus V31X501) and were classified under the following criteria: The carcass was considered a major component of the FFM, the previously shaved skin as a FM component and a third component, the residual mass, was composed of blood and viscera. From the skin, the previously dissected fat mass was extracted in accordance with the Bligh and Dyer method, which comprises homogenization of a 1:2:1 mixture of methanol, chloroform and tissue (17).

$R N A$ isolation and reverse transcription-semi-quantitative polymerase chain reaction ( $R T-s q P C R)$ assay. Total RNA was isolated by tissue lysis with TRIzol reagent (Invitrogen; Thermo Fisher Scientific, Inc., Waltham, MA, USA) from tissue samples of the stomach and central aorta to measure ghrelin and LPL, respectively. The RT reactions were performed with a High Capacity cDNA RT kit (cat. no. 4368813; Applied Biosystems; Thermo Fisher Scientific, Inc.) using $3 \mu \mathrm{g}$ RNA 
with $0.8 \mu 1$ of $25 \mathrm{X}$ deoxynucleotidetriphosphates (dNTPs; $100 \mathrm{mM}$ ), $2 \mu 110 \mathrm{X}$ random primers, $2 \mu 1$ 10X RT buffer and $1 \mathrm{U}$ Multiscribe RT in a final volume of $20 \mu \mathrm{l}$ topped up with nuclease-free water using a thermocycler (FGEN02TP; Techne Genius; Cole-Parmer, Stone, UK) with the following incubation conditions: $25^{\circ} \mathrm{C}$ for $10 \mathrm{~min}, 37^{\circ} \mathrm{C}$ for $120 \mathrm{~min}$ and $85^{\circ} \mathrm{C}$ for $5 \mathrm{~min}$. Each PCR was performed in a final volume of $25 \mu \mathrm{l}$ containing $0.25 \mu \mathrm{l}$ complementary (c)DNA, $2.5 \mu \mathrm{l}$ 10X PCR Buffer Minus Mg, $10 \mathrm{mM}$ dNTPs mix, $50 \mathrm{mM}$ $\mathrm{MgCl}_{2}, 10 \mu \mathrm{M}$ of each ghrelin, LPL and GAPDH-specific primer and $0.125 \mathrm{U}$ Taq polymerase (all, Invitrogen; Thermo Fisher Scientific, Inc). A 347-DNA fragment coding for rat ghrelin was amplified with forward primer 5'-TTGAGCCCA GAGCACCAGAAA-3' and reverse primer 5'-AGCTTCTGC CTCCTCTGCAACT-3', with the oligonucleotides designed from the sequence of the gene (GenBank accession no. AB029433.1). In the case of LPL, a 292-bp DNA fragment was amplified with forward primer 5'-CCCCAGCAAGGC ATACAGGT-3' and reverse primer 5'-CGGCAGGGTGAA GGGAATGT-3', with the oligonucleotide designed from the sequence of the gene (GenBank accession no. NM_012598.2). As an internal control for amplification, a 207-bp fragment of rat GAPDH was amplified from the same cDNA, with the forward primer 5'-AGACAGCCGCATCTTCTTGT-3' and the reverse primer 5'-CTTGCCGTGGGTAGAGTCAT-3' designed from the sequence of the gene (GenBank accession no. NM_017008.4). All primers used in the experiment were custom-made (Invitrogen; Thermo Fisher Scientific, Inc.). Optimal PCR conditions were as follows: an initial incubation of $94^{\circ} \mathrm{C}$ for $3 \mathrm{~min}$ followed by 35 cycles at $94^{\circ} \mathrm{C}$ for $30 \mathrm{sec}$, $56^{\circ} \mathrm{C}$ for $30 \mathrm{sec}$ and $72^{\circ} \mathrm{C}$ for $30 \mathrm{sec}$ and a final extension step at $72^{\circ} \mathrm{C}$ for $10 \mathrm{~min}$. PCR products were analyzed in ethidium bromide-stained agarose gels (Invitrogen; Thermo Fisher Scientific, Inc.). They underwent horizontal gel electrophoresis for $80 \mathrm{~min}$ at $60 \mathrm{~V}$ and $15 \mathrm{~min}$ staining in ethidium bromide solution $5 \mu \mathrm{g} / \mathrm{ml}$ (Sigma-Aldrich; Merck KGaA). The intensity of the amplified bands was analyzed using QuantityOne ${ }^{\circledR}$ version 4.6.6 software (Bio-Rad Laboratories, Inc., Hercules, CA, USA). Band intensities were normalized to the GAPDH signal (ghrelin/GAPDH and LPL/GAPDH rates).

Statistical analysis. Values are expressed as the mean \pm standard error of the mean. Comparisons among groups were performed using two-way analysis of variance (ANOVA) followed by Bonferroni's post-hoc test using GraphPad Prism 6.0 (GraphPad Software, Inc., La Jolla, CA, USA) in most experiments. PCR results were analyzed by one-way ANOVA followed by Tukey's test. $\mathrm{P}<0.05$ was considered to indicate a significant difference between groups.

\section{Results}

Body weight, length, food consumption and specific weight gain. From day 40 of treatment, all groups exhibited obvious differences in body weight until the end of the experiment. A higher weight gain was identified in the OVX, OVX+LA and LA groups (216.1, 175.4 and $183.7 \%$, respectively) compared with that in the CTRL group (150.1\%). At the end of the experiment, the groups treated with LA had a significantly higher weight compared with that in their equivalent groups who

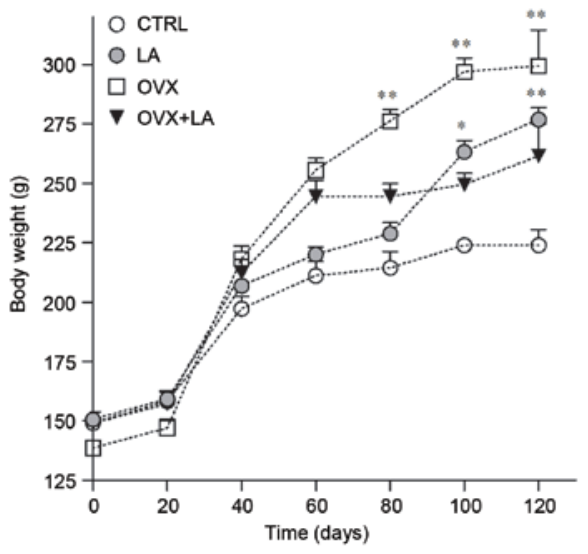

Figure 1. Body weight changes in the experimental groups over 120 days Values are expressed as the mean \pm standard error of the mean. ${ }^{*} \mathrm{P}<0.05$; ${ }^{* *} \mathrm{P}<0.01$ for comparisons between equivalent groups (LA vs. CTRL and OVX vs. OVX+LA). Groups: CTRL, untreated rats; LA, rats treated with LA (5 $\mu \mathrm{g} / \mathrm{kg}$ /every 3 days); OVX, ovariectomized group; OVX+LA, ovariectomized rats treated with LA. LA, leuprolide acetate.

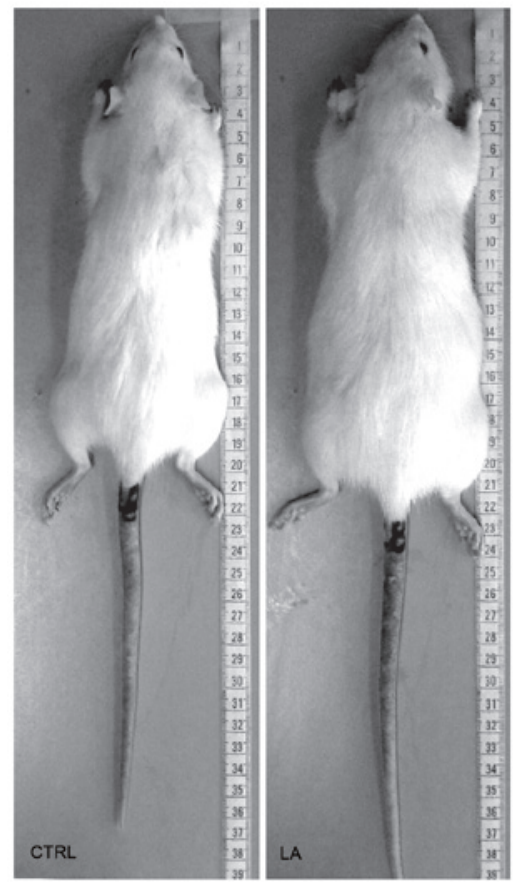

Figure 2. Representative images comparing the length of an intact CTRL and an intact LA rat at 120 days. The nose-anus length was measured during all experiments. CTRL, untreated rats; LA, rats treated with LA $(5 \mu \mathrm{g} / \mathrm{kg} / \mathrm{every}$ 3 days). LA, leuprolide acetate.

received saline only (Fig. 1). Regarding body length (Fig. 2), animals that received LA injections had a slight increment in their body length $(\sim 4.3 \%)$ in comparison with LA-untreated animals at 120 days (data not shown).

Food consumption (FC) was positively correlated with body weight (BW), as presented in Fig. 3A, which correlates the cumulative results of FC and BW (measured once a day and weekly, respectively) every 20 days for the duration of the experiment. High correlation was observed between food intake and weight gain in the LA and OVX+LA groups. The OVX group consumed more food and gained more weight compared with the CTRL group, which practically did not 

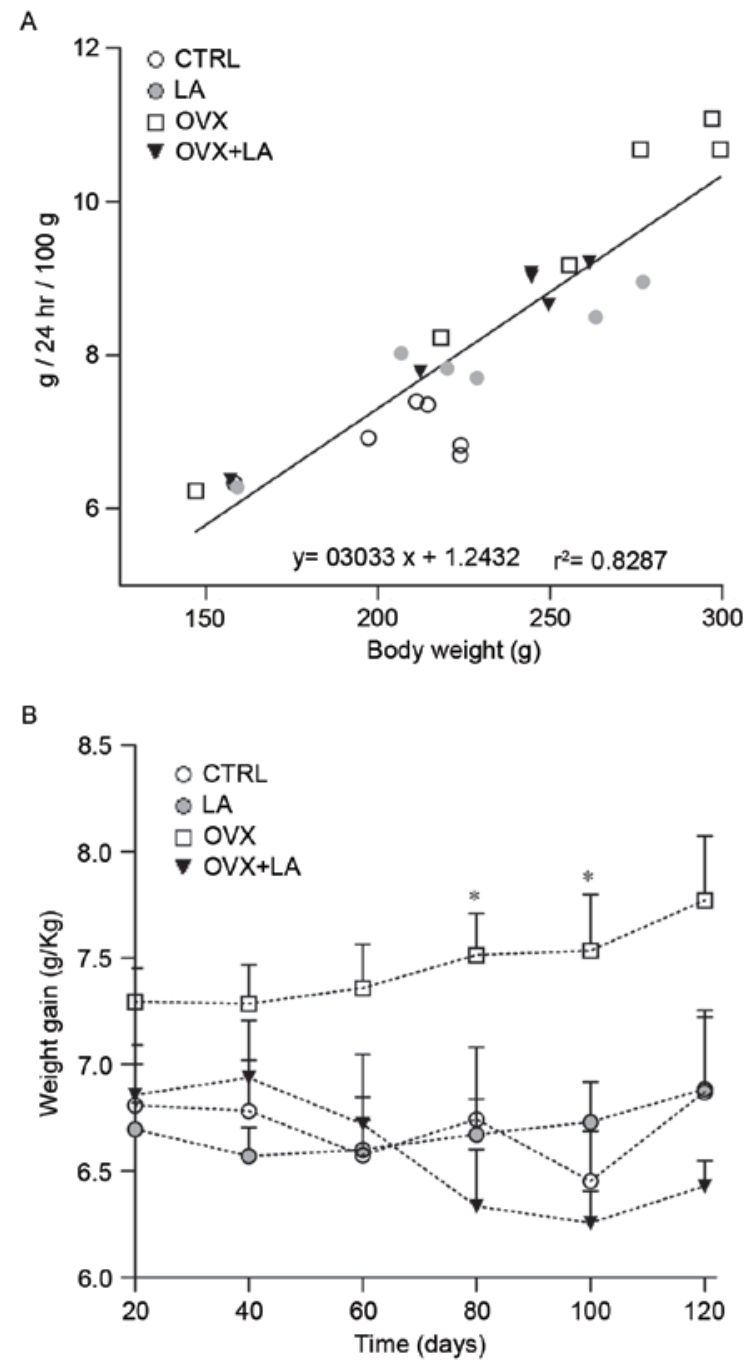

Figure 3. (A) Regression analysis of food consumption (g/24 h/100 g) and body weight $(\mathrm{g})$ in all experimental rats. A significant association between food consumption and body weight was observed. (B) Specific rate of body mass gain. Values are expressed as the mean \pm standard error of the mean ${ }^{*} \mathrm{P}<0.05$ vs. OVX+LA group. Groups: CTRL, untreated rats; LA, rats treated with LA ( $5 \mu \mathrm{g} / \mathrm{kg} /$ every 3 days); OVX, ovariectomized group; OVX+LA, ovariectomized rats treated with LA. LA, leuprolide acetate.

change their food consumption and weight gain was minimal $(\mathrm{r}=0.874, \mathrm{P}<0.0001, \mathrm{FC}$ vs. BW). Over the entire experiment, the specific rate of body mass gain in the OVX group was higher compared with that in the other groups. No significant differences were observed between the CTRL and LA groups; however, the OVX+LA group exhibited a marked reduction in weight gain compared with that in the OVX group with significant differences on days 80 ( $6.33 \pm 0.26$ vs. $7.51 \pm 0.19 \mathrm{~g} ; \mathrm{P}<0.05)$ and 100 of treatment $(6.25 \pm 0.15$ vs. $7.53 \pm 0.26 \mathrm{~g} ; \mathrm{P}<0.05$; Fig. 3B). At 120 days there were notable differences in weight gain between the two groups but they were not statistically significant $(6.4 \pm 0.12$ vs. $7.7 \pm 0.30 \mathrm{~g})$.

Body composition measured by hydrodensitometry. Significant differences in FFM (data not shown) and FM were observed on days 100 and 120 between equivalent groups (CTRL vs. LA and OVX vs. OVX+LA). The FM in the LA group was $18.3 \%$ higher compared with that in the CTRL group at day

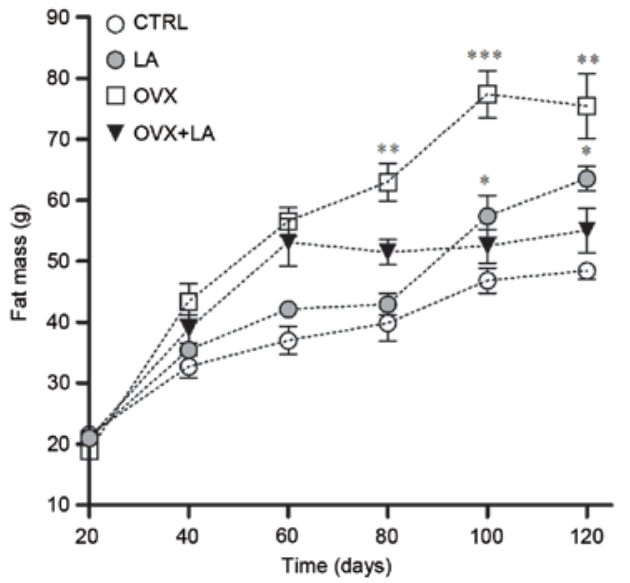

Figure 4. Fat mass determined by hydrodensitometry. Values are expressed as the mean \pm standard error of the mean. ${ }^{*} \mathrm{P}<0.05 ;{ }^{* *} \mathrm{P}<0.01 ;{ }^{* * *} \mathrm{P}<0.001$ for comparisons between equivalent groups (LA vs. CTRL and OVX vs. OVX+LA). Groups: CTRL, untreated rats; LA, rats treated with LA (5 $\mu \mathrm{g} / \mathrm{kg} /$ every 3 days); OVX, ovariectomized group; OVX+LA, ovariectomized rats treated with LA. LA, leuprolide acetate.

$100(\mathrm{P}<0.05$; Fig. 4$)$ and $23.9 \%$ at day 120 (P<0.05; Fig. 4). Furthermore, the OVX+LA group had a significantly lower FM compared with that in the OVX group on days 80,100 and 120. At the end of the experiment, the FM in the OVX group was increased to $27.01 \%$ compared with that in the OVX+LA group $(\mathrm{P}<0.01$; Fig. 4$)$.

Carcass analysis and total lipids extracted from skin. All groups exhibited substantial changes in residual mass and skin weight compared with CTRL animals (data not shown). All groups exhibited substantial changes skin weight compared with the CTRL animals. Analyses from equivalent groups for each component revealed significant differences for skin weight in the case of LA vs. CTRL at day $100(36.2 \pm 1.0$ vs. $28.5 \pm 0.3 \mathrm{~g}$; $\mathrm{P}<0.05)$ and day 120 (38.6 \pm 2.3 vs. $28.4 \pm 0.9 \mathrm{~g} ; \mathrm{P}<0.01$; data not shown). No substantial differences were found between the OVX and OVX+LA groups; however, at day 120, each of these two groups had higher values than the CTRL and LA groups in skin weight (data not shown). At the end of the experiment, the carcass weight in the LA group had increased by $\sim 179 \%$, the CTRL group had increased by $147 \%$, the carcass weight in the OVX group exhibited a high increase of $\sim 194 \%$ and an increase of $164 \%$ was observed in the OVX+LA animals in comparison from the basal values of each group (Fig. 5). The comparisons between equivalent groups resulted in a significantly higher carcass weight for LA group in comparison with CTRL group from day 40 to 120 (day $40,139.5 \pm 3.1$ vs. $115.3 \pm 3.4 \mathrm{~g} ; \mathrm{P}<0.01$; day $60,139.7 \pm 1.4$ vs. $119.5 \pm 6.1 \mathrm{~g} ; \mathrm{P}<0.05$; day $80,141.3 \pm 1.9$ vs. $120.8 \pm 4.6 \mathrm{~g} ; \mathrm{P}<0.05$; day $100,155.1 \pm 6.3$ vs. $134.9 \pm 1.4 \mathrm{~g} ; \mathrm{P}<0.05$; day $120,166.3 \pm 2.2$ vs. $140.3 \pm 5.6 \mathrm{~g}$; $\mathrm{P}<0.01$; Fig. 5). The OVX and OVX+LA groups had similar carcass weights from 20 to 80 days and a significant difference at 100 days $(188.1 \pm 9.1$ vs. $163.9 \pm 1.1 \mathrm{~g} ; \mathrm{P}<0.05)$, however this difference was reduced at 120 days $(180.05 \pm 2.3$ vs. $161.2 \pm 1.2$ g; P>0.05; Fig. 5).

The PI was correlated with the lipid extracted from the skin of all groups ( $r=0.7603, \mathrm{P}<0.0001$; Fig. 6). The highest values of PI and total lipid extracted from skin were observed 


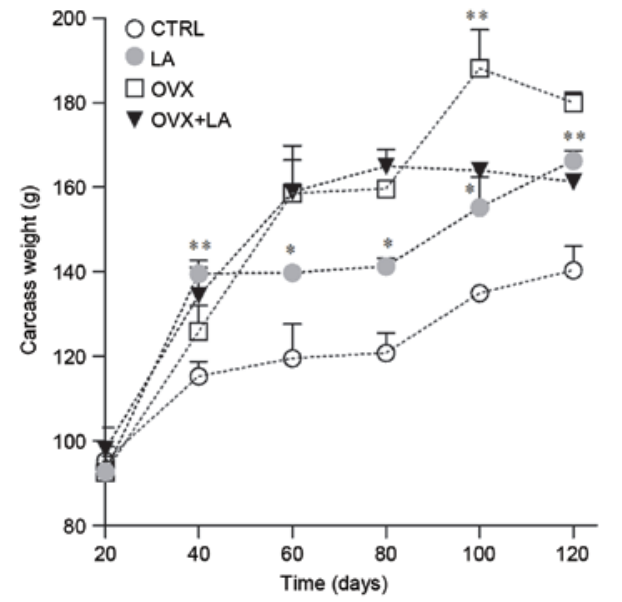

Figure 5. Assay of carcass weight from dissection study considering this tissue as a major component of fat-free mass. Every 20 days, 4 rats per group were used for the dissection assay. Values are expressed as the mean \pm standard error of the mean. " $\mathrm{P}<0.05 ;{ }^{* *} \mathrm{P}<0.01$ for comparisons between equivalent groups (LA vs. CTRL and OVX vs. OVX+LA). Groups: CTRL, untreated rats; LA, rats treated with LA (5 $\mu \mathrm{g} / \mathrm{kg} /$ every 3 days); OVX, ovariectomized group; OVX+LA, ovariectomized rats treated with LA. LA, leuprolide acetate.

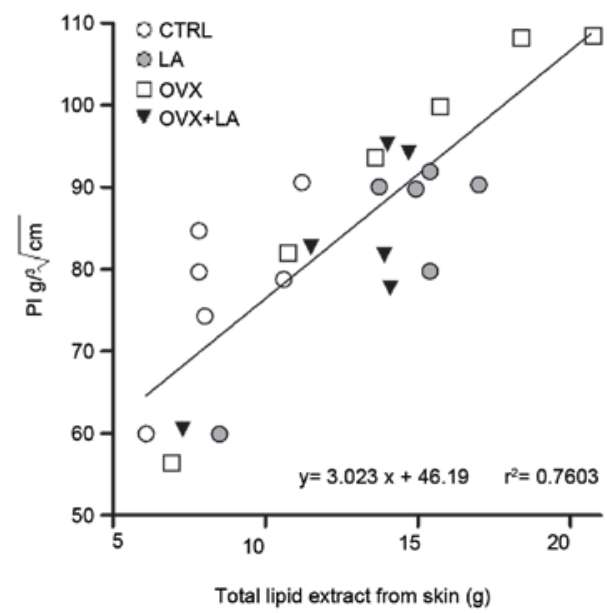

Figure 6. Regression analysis of ponderal index $(\mathrm{g} / \sqrt[3]{ } \mathrm{cm})$ and total lipids extracted from skin $(\mathrm{g})$ for all groups from 0-120 days. A significant correlation between the ponderal index and lipids extracted from the skin was identified. Groups: CTRL, untreated rats; LA, rats treated with LA ( $5 \mu \mathrm{g} / \mathrm{kg} /$ every 3 days); OVX, ovariectomized group; OVX+LA, ovariectomized rats treated with LA. LA, leuprolide acetate.

in OVX animals, while the lowest values were in the CTRL group. The LA and OVX+LA had similar results in this correlation analysis (Fig. 6).

Ghrelin and LPL mRNA expression. As presented in Fig. 7A, ghrelin mRNA expression in the LA group increased by $20 \%$ compared with that in the CTRL group at the end of the experiment $(\mathrm{P}<0.01)$. Furthermore, simultaneous treatment with LA resulted in $24 \%$ less ghrelin mRNA expression in comparison with that in the OVX group $(\mathrm{P}<0.05)$. Indeed, the OVX group had the highest ghrelin mRNA expression among all groups. Similar results were obtained for LPL mRNA (Fig. 7B); the LA group had a $\sim 20 \%$ higher expression than the CTRL group $(\mathrm{P}<0.05)$, and of note, the OVX+LA group had $\sim 18 \%$ less LPL expression in comparison with that in the OVX group $(\mathrm{P}<0.01)$.
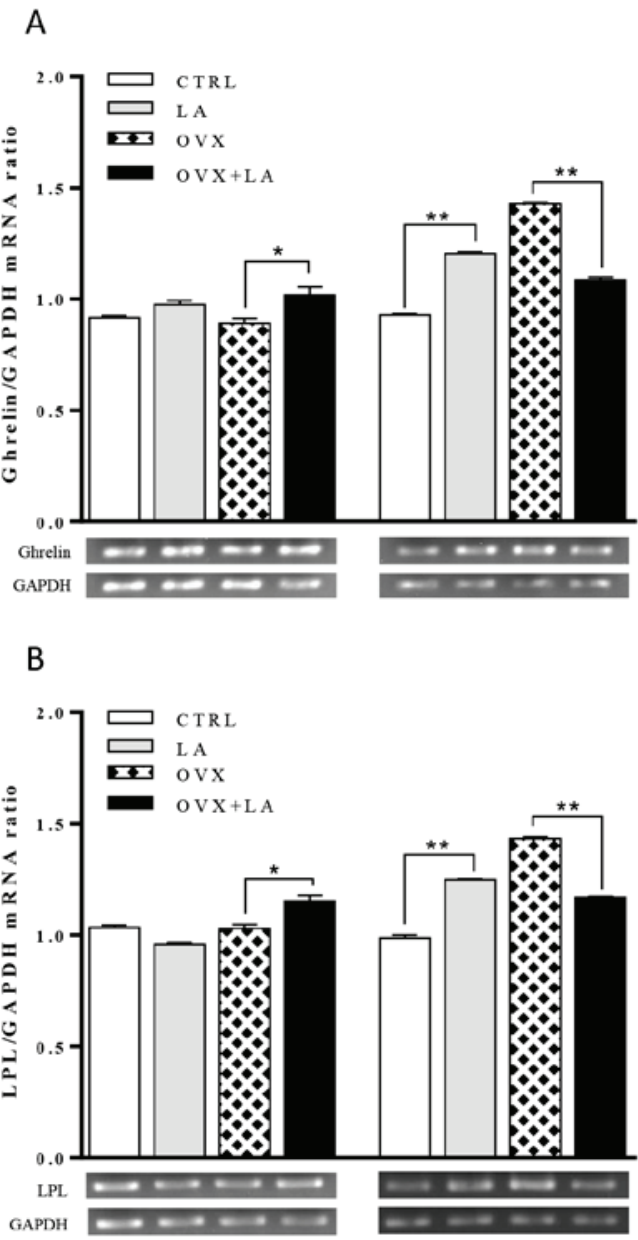

Figure 7. Changes in ghrelin and LPL mRNA expression at 20 and 120 days of the experiment. (A) PCR products of ghrelin ( $347 \mathrm{bp}$ ) and mRNA expression. (B) PCR products of LPL (292 bp) and mRNA expression. All the results of mRNA expression were normalized to GAPDH. Values are expressed as the mean \pm standard error of the mean. ${ }^{*} \mathrm{P}<0.05 ;{ }^{* *} \mathrm{P}<0.01$ as indicated. Groups: CTRL, untreated rats; LA, rats treated with LA ( $5 \mu \mathrm{g} / \mathrm{kg} /$ every 3 days); OVX, ovariectomized group; OVX+LA, ovariectomized rats treated with LA. LA, leuprolide acetate; PCR, polymerase chain reaction; LPL, lipoprotein lipase.

\section{Discussion}

It has been reported that LA is a safe drug for treating certain types of cancer and hormonal disorders associated with the reproductive system (7). Recently, GnRH and its agonist LA have been used in experimental studies on neuronal regeneration (8-10). However, weight gain is one of the side effects reported more frequently by these treatments, while only few studies have addressed body composition and the possible pathways responsible for this. The present study demonstrated that LA promoted changes in body composition and variations in the mRNA expression of ghrelin and LPL in non-ovariectomized and ovariectomized rats. It was revealed that long-term LA administration causes an increase in body weight in rats compared with that in the control group. This subsequent effect has been reported in humans mainly in treatments for precocious puberty using GnRH and LA $(18,19)$, as well as cancer $(20,21)$ and fertility regulation $(22,23)$.

Of note, the OVX group demonstrated the highest weight gain among all other groups (CTRL, OVX+LA and LA). OVX 
by itself causes this condition, which is in accordance with previous studies (24). Nguyen et al 2004 (25), reported a 53\% increase in body weight in cats after OVX compared with only $27 \%$ in a group that underwent sham surgical intervention. This increase in corporal weight was highly associated with food consumption. In the present study, an association was observed between high food consumption and increased body weight, which was also supported by the ovariectomy-specific weight gain due to the weight in the OVX group being comparatively higher during the entire experiment. In an osteoporosis model induced by ovariectomy, Jiang et al 2008 (26) identified that hyperphagia is the main cause of gain weight in Sprague Dawley rats. An outcome to highlight is the stabilization in weight gain for animals in the OVX+LA group, which had minimum variations from day 60 of treatment until the end of the experiment.

Regarding the analysis of body composition by hydrodensitometry, an increase of FM was identified in the LA group at the end of the experiment and no difference was observed in FFM when compared with that in the CTRL group. In clinical trials with androgen deprivation therapy using LA to treat prostate cancer, an increase in weight and FM measured by dual-energy $\mathrm{x}$-ray absorptiometry and bioelectrical impedance devices has been reported $(21,27)$. It is well established that long-term therapy with $\mathrm{GnRH}$ agonists causes a desensitization of the pituitary gonadotrophs, which leads to a complete or acute lack of response of follicle-stimulatory hormone or luteinizing hormone in eugonadal subjects (28). This condition restrains gonadal steroidal production avoiding a negative feedback at the hyphophyseal level in GnRH secretion (29). However, not only steroidal production exerts this function; Shimizu et al (30) reported reduced levels of circulating estradiol $\left(\mathrm{E}_{2}\right)$ in response to total bilateral ovariectomy and increases in the mRNA expression of neuropeptide Y (NPY) at the hyphophyseal level. It is possible that NPY, an orexigenic peptide, may induce hyperphagia with subsequent weight gain. This may explain for the weight gain in the AL group, in which long-term administration of LA partially decreased the production of $\mathrm{E}_{2}$ and favored an increase in food consumption. It has been reported that decreasing $\mathrm{E}_{2}$ causes not only an overproduction of NPY, but also an impaired leptin sensitivity in ovariectomized rats (31). Estrogen replacement has been studied as a method to prevent increases in body weight in experimental and clinical trials $(32,33)$. However, in the present study, the OVX+LA group exhibited less FM and FFM compared with that in the OVX group.

To confirm the results of previous in vivo assays, the present study demonstrated that the LA group had a higher FFM (carcass weight) and FM (skin weight) than the CTRL group, while the OVX+LA and OVX groups had a similar skin weight but the carcass weight in the OVX+LA group did not change from day 60 . Several studies indicated that therapy with GnRH agonists modifies the body composition with the FM being the main affected component and slight reductions in the FFM (20,34-36). However, these therapies were performed to treat specific pathophysiological conditions with no dietary control. In addition, the present study identified a positive correlation between PI and the total lipid extract from the skin, which means that animal size is not only associated with this indicator but also with a FM under the skin.
At present, no information is available on the effect of the use of GnRH agonists after ovariectomy or its direct long-term effects on body composition under these conditions. Furthermore, a recent study report that GnRH may have different roles outside the hypothalamus-pituitary-reproductive axis (34).

The present study reported an increased ghrelin mRNA expression in animals in the LA group, which also had a high food consumption and weight gain in comparison with CTRL animals. At present, the manufacturers of commercial LA preparations warn about rapid weight gain during treatments, for instance in central precocious puberty $(18,37)$, but these phenomena are not well explained. The present study indicated that long-term treatment with LA increases ghrelin mRNA expression, which probably leads to hyperphagia and a subsequent weight gain with body composition changes. As previously reported, the present study observed changes in food intake, body weight and fat mass gain (38). In addition, the mRNA expression of ghrelin and LPL in the OVX group was even higher than that in the LA group at the end of the experiment (120 days). Likewise, the mRNA expression of LPL was higher in the LA group compared with that in the CTRL group, each group (OVX and LA) had a direct effect by ovariectomy and LA administration, respectively. These circumstances may be favorable towards an increase in weight an FM deposition due to high LPL activity. Studies have reported on the effect of ghrelin administration and how it modifies food intake, it has been previously mentioned that suppression of estrogen is associated with obesity development in mammals and there is evidence that estrogen blocks the transcription of the LPL gene (39-41). However, the results of the present study may indicate that LA had a different effect in ovariectomized rats, as a downregulation in ghrelin and LPL mRNA expression to levels similar to those in the LA group were observed at the end of the experiment, which was probably associated with a decrease in food consumption and less FM deposition, which in fact corresponded to the results on body composition. It may be hypothesized that by LA administration stimulates a replacement of steroidal secretion in ovariectomized rats in other specialized tissues, which was supported by previous reports on the GnRH receptor outside of the hypothalamic-pituitary-reproductive axis (42).

In conclusion, the present study indicated that long-term administration of LA promoted changes in weight and body composition in ovariectomized and non-ovariectomized rats. It also promoted increments in mRNA expression of ghrelin and LPL in non-ovariectomized animals while a downregulation was present in ovariectomized animals with the same treatment, which probably affected food consumption and adipogenesis. To the best of our knowledge, the present study was one of the first describing the direct effect of LA on body composition in the long term, taking into consideration a controlled diet and the absence of pathophysiological events. LA is a therapeutic drug that is currently widely used throughout the world, and experimental models such as that of the present study may serve to elucidate the mechanisms involved in changes in body composition or for nutritional prophylaxis in subjects treated with GnRH analogs. To explain the mechanisms implied to this phenomenon, further experiments should be performed. 


\section{Acknowledgements}

The authors would like to thank Moisés Altamira-Camacho and Irma Hernández-Jasso for their technical support. The present study was supported by a grant from the National Council of Science and Technology Mexico (grant no. 467237).

\section{References}

1. Quintanar JL and Salinas E: Neurotrophic effects of GnRH on neurite outgrowth and neurofilament protein expression in cultured cerebral cortical neurons of rat embryos. Neurochem Res 33: 1051-1056, 2007.

2. Prange-Kiel J, Jarry H, Schoen M, Kohlmann P, Lohse C, Zhou L and Rune GM: Gonadotropin-releasing hormone regulates spine density via its regulatory role in hippocampal estrogen synthesis. J Cell Biol 180: 417-426, 2008.

3. Conn PM and Crowley WF Jr: Gonadotropin-releasing hormone and its analogs. Annu Rev Med 45: 391-405, 1994.

4. Periti P, Mazzei T and Mini E: Clinical pharmacokinetics of depot leuprorelin. Clin Pharmacokinet 41: 485-504, 2002.

5. Sennello LT, Finley RA, Chu SY, Jagst C, Max D, Rollins DE and Tolman KG: Single-dose pharmacokinetics of leuprolide in humans following intravenous and subcutaneous administration. J Pharm Sci 75:158-60, 1986.

6. Lønning PE and Lien EA: Pharmacokinetics of anti-endocrine agents. Cancer Surv 17: 343-370, 1993.

7. Wilson AC, Meethal SV, Bowen RL and Atwood CS: Leuprolide acetate: A drug of diverse clinical applications. Expert Opin Investig Drugs 16: 1851-1863, 2007.

8. Guzmán-Soto I, Salinas E, Hernández-Jasso I and Quintanar JL Leuprolide Acetate, a GnRH Agonist, improves experimental autoimmune encephalomyelitis: A possible therapy for multiple sclerosis. Neurochem Res 37: 2190-2197, 2012.

9. Calderón-Vallejo D and Quintanar JL: Gonadotropin-releasing hormone treatment improves locomotor activity, urinary function and neurofilament protein expression after spinal cord injury in ovariectomized rats. Neurosci Lett 515: 187-190, 2012.

10. DíazGalindoC,Gómez-GonzálezB,SalinasE,Calderón-VallejoD, Hernández-Jasso I, Bautista E and Quintanar JL: Leuprolide acetate induces structural and functional recovery of injured spinal cord in rats. Neural Regen Res 10: 1819-1824, 2015

11. Gevers EF, Wit JM and Robinson IC: Effects of long-term gonadotropin-releasing hormone analog treatment on growth, growth hormone $(\mathrm{GH})$ Secretion, GH Receptors, and GH-binding protein in the rat. Pediatr Res 43: 111-120, 1998.

12. Müller TD, Nogueiras R, Andermann ML, Andrews ZB, Anker SD, Argente J, Batterham RL, Benoit SC, Bowers CY, Broglio F, et al: Ghrelin. Mol Metab 4: 437-460, 2015.

13. Wang H and Eckel RH: Lipoprotein lipase: From gene to obesity. Am J Physiol Endocrinol Metab 297: E271-E288, 2009.

14. Novelli EL, Diniz YS, Galhardi CM, Ebaid GM, Rodrigues HG, Mani F, Fernandes AA, Cicogna AC and Novelli Filho JL: Anthropometrical parameters and markers of obesity in rats. Lab Anim 41: 111-119, 2007

15. Hohl R, de Oliveira RB, Vaz de Macedo D and Brenzikofer R: Apparatus for measuring rat body volume: A methodological proposition. J Appl Physiol (1985) 102: 1229-1234, 2007.

16. Muscaritoli M, Gleason JR, Meguid MM and Lukaski HC: Densitometry-based equations for estimating body composition in Fischer rats. Nutrition 9: 439-445, 1993.

17. Bligh EG and Dyer WJ: A rapid method of total lipid extraction and purification. Can J Biochem Physiol 37: 911-917, 1959.

18. Lee SJ, Yang EM, Seo JY and Kim CJ: Effects of gonadotropin-releasing hormone agonist therapy on body mass index and height in girls with central precocious puberty. Chonnam Med J 48: 27-31, 2012.

19. Neely EK, Lee PA, Bloch CA, Larsen L, Yang D, Mattia-Goldberg C and Chwalis K: Leuprolide acetate 1-month depot for central precocious puberty: Hormonal suppression and recovery. Int J Pediatr Endocrinol 2010: 398639, 2010.

20. Basaria S, Lieb J II, Tang AM, DeWeese T, Carducci M, Eisenberger $M$ and Dobs AS: Long-term effects of androgen deprivation therapy in prostate cancer patients. Clin Endocrinol (Oxf) 56: 779-786, 2002.

21. Smith MR: Changes in fat and lean body mass during androgen-deprivation therapy for prostate cancer. Urology 63: 742-745, 2004.
22. Herbert CA and Trigg TE: Applications of GnRH in the control and management of fertility in female animals. Anim Reprod Sci 88: 141-153, 2005

23. Lessey BA: Medical management of endometriosis and infertility. Fertil Steril 73: 1089-1096, 2000.

24. Wei A, Fascetti AJ, Kim K and Ramsey JJ: Post-castration variations in weight gain in a cohort of young adult male cats. J Nutr Sci 3: e37, 2014.

25. Nguyen PG, Dumon HJ, Siliart BS, Martin LJ, Sergheraert R and Biourge VC: Effects of dietary fat and energy on body weight and composition after gonadectomy in cats. Am J Vet Res 65: 1708-1713, 2004

26. Jiang JM, Sacco SM and Ward WE: Ovariectomy-induced hyperphagia does not modulate bone mineral density or bone strength in rats. J Nutr 138: 2106-2110, 2008.

27. Stoch SA, Parker RA, Chen L, Bubley G, Ko YJ, Vincelette A and Greenspan SL: Bone loss in men with prostate cancer treated with gonadotropin-releasing hormone agonists. J Clin Endocrinol Metab 86: 2787-2791, 2001

28. Meldrum DR, Chang RJ, Lu J, Vale W, Rivier J and Judd HL: 'Medical oophorectomy' using a long-acting gnrh agonist-a possible new approach to the treatment of endometriosis. J Clin Endocrinol Metab 54: 1081-1083, 1982.

29. Ohtsuka S, Terakawa N, Shimizu I, Sakata M, Mizutani T, Miyake A, Tanizawa O and Aono T: Studies on GnRH agonist suppression of estrogen production in patients with endometriosis. Endocrinol Jpn 36: 611-619, 1989.

30. Shimizu H, Ohtani K, Kato Y, Tanaka Y and Mori M: Withdrawal of [corrected] estrogen increases hypothalamic neuropeptide $Y$ (NPY) mRNA expression in ovariectomized obese rat. Neurosci Lett 204: 81-84, 1996.

31. Ainslie DA, Morris MJ, Wittert G, Turnbull H, Proietto J and Thorburn AW: Estrogen deficiency causes central leptin insensitivity and increased hypothalamic neuropeptide Y. Int J Obes Relat Metab Disord 25: 1680-1688, 2001.

32. Litwak SA, Wilson JL, Chen W, Garcia-Rudaz C, Khaksari M, Cowley MA and Enriori PJ: Estradiol prevents fat accumulation and overcomes leptin resistance in female high-fat diet mice. Endocrinology 155: 4447-4460, 2014.

33. Matysková R, Zelezná B, Maixnerová J, Koutová D, Haluzík M and Maletínská L: Estradiol supplementation helps overcome central leptin resistance of ovariectomized mice on a high fat diet. Horm Metab Res 42: 182-186, 2010.

34. Yamasaki H, Douchi T, Yamamoto S, Oki T, Kuwahata R and Nagata Y: Body fat distribution and body composition during GnRH agonist therapy. Obstet Gynecol 97: 338-342, 2001.

35. Boxer RS, Kenny AM, Dowsett R and Taxel P: The effect of 6 months of androgen deprivation therapy on muscle and fat mass in older men with localized prostate cancer. Aging Male 8: 207-212, 2005.

36. Park HK, Lee HS, Ko JH, Hwang IT, Lim JS and Hwang JS: The effect of gonadotrophin-releasing hormone agonist treatment over 3 years on bone mineral density and body composition in girls with central precocious puberty. Clin Endocrinol (Oxf) 77: 743-748, 2012.

37. Kim EY: Long-term effects of gonadotropin-releasing hormone analogs in girls with central precocious puberty. Korean J Pediatr 58: 1-7, 2015.

38. Theander-Carrillo C, Wiedmer P, Cettour-Rose P, Nogueiras R, Perez-Tilve D, Pfluger P, Castaneda TR, Muzzin P, Schürmann A, Szanto I, et al: Ghrelin action in the brain controls adipocyte metabolism. J Clin Invest 116: 1983-1993, 2006.

39. Pedersen SB, Børglum JD, Møller-Pedersen T and Richelsen B: Effects of in vivo estrogen treatment on adipose tissue metabolism and nuclear estrogen receptor binding in isolated rat adipocytes. Mol Cell Endocrinol 85: 13-19, 1992.

40. Homma H, Kurachi H, Nishio Y, Takeda T, Yamamoto T, Adachi K, Morishige K, Ohmichi M, Matsuzawa Y and Murata Y: Estrogen suppresses transcription of lipoprotein lipase gene. Existence of A unique estrogen response element on the lipoprotein lipase promoter. J Biol Chem 275: 11404-11411, 2009.

41. Pedersen SB, Børglum JD, Eriksen EF and Richelsen B: Nuclear estradiol binding in rat adipocytes. Regional variations and regulatory influences of hormones. Biochim Biophys Acta 1093: 80-86, 1991.

42. Skinner DC, Albertson AJ, Navratil A, Smith A, Mignot M, Talbott $\mathrm{H}$ and Scanlan-Blake N: GnRH effects outside the hypothalamo-pituitary-reproductive axis. J Neuroendocrinol 21: 282-292, 2009. 